\title{
WIRED FOR SOCIAL INTERACTION: WHAT AN INTERDISCIPLINARY APPROACH FROM NEUROBIOLOGY, EVOLUTIONARY BIOLOGY, AND SOCIAL EDUCATION WORK CAN TEACH US ABOUT PSYCHOLOGICAL TRAUMA
}

\section{Isabella Sarto-Jackson}

\begin{abstract}
The human brain is equipped with physiological, neural, and cognitive capacities that enable it to respond flexibly to ever-changing natural and social conditions. This capacity of the brain to reorganize itself, called neuroplasticity, is particularly marked in childhood. The high malleability of the brain at this stage provides the basis for wide-ranging learning, but leaves it vulnerable to negative environmental and social factors. Neuroplastic events that occur in response to abusive or neglecting environments can strongly interfere with the adaptive shaping of neural pathways between the prefrontal cortex and the limbic system, compromising judgment and self-control. Traumatic experiences during development can also have other effects on brain plasticity that are mediated by epigenetic mechanisms, and these effects can impair the developing oxytocin system, adversely affecting attachment and bonding. Mature individuals seek out niches that match the internal mental structures shaped during their early years, and will even alter the environment to make it match the internal structures. In the case of those who suffered childhood abuse, this can lead to maltreatment of the next generation. Addressing the societal challenge of child abuse and maltreatment requires broad interdisciplinary endeavors, uniting neuroscientists and social education workers to break the vicious circle.
\end{abstract}

Keywords: neuroplasticity, childhood abuse, developmental trauma, posttraumatic stress disorder, social niche construction, maladaptation

Acknowledgement: This manuscript aims to elaborate some points made in the lecture I gave at the 33rd FICE Congress held in Vienna in 2016. I am indebted to the program committee of the 33rd FICE Congress for having put together a highly exciting event with excellent contributions. I would like to especially thank Hermann Radler, president of FICE International; Peter Sarto, ombudsman for children and adolescents in residential communities of the city administration of Vienna; and Alexander Binder-Degenschild, a social pedagogue with FICE Austria, for fruitful discussions and valuable insights into their fields of expertise.

Isabella Sarto-Jackson PhD is Executive Manager of the Konrad Lorenz Institute for Evolution and Cognition Research, Martinstrasse 12, $3400 \quad$ Klosterneuburg, Austria. Email: isabella.sarto-jackson@kli.ac.at 
International Journal of Child, Youth and Family Studies (2018) 9(1): 9-30

For more than a century, two diametrically opposed views on human brain development prevailed in the sciences. While one camp emphasized a deterministic perspective that considered brain architecture to be innate, largely hardwired and encoded by genes, a second assumed the brain to be a "blank slate" with boundless malleability (Bach-y-Rita, 1967; BaronCohen, 2003; Brizendine, 2006; Doidge, 2007; Golgi, 1898; Gollin, 1981; Grossi, 2017; Lugaro, 1909). In recent decades these two camps have converged to a significant extent. The second camp has begun to take genetic factors into account in investigations on human behavior and cognitive development, while the first has increasingly acknowledged the importance of environmental and social influences on human brain development (Azmitia, 2007; Kandel, Schwartz, \& Jessell, 2000; Lillard \& Erisir, 2014). In fact, there is now ample evidence that biological features, ranging from an organism's behavior to its morphology and anatomy, and even the genetic information in its DNA, can be modulated by the environment (Mitchell, Schneper, \& Notterman, 2016; Szyf, 2011; Tognini, Napoli, \& Pizzorusso, 2015). These findings apply to all organisms, including humans.

The interplay between biology and the environment is particularly relevant for human brain development, suggesting that the brain is not an instructional, but a selectional system (Edelman, 1987). In an instructional system, an incoming signal (genetic determinant, environmental trigger, etc.) is the primary and necessary event that shapes a system's structure and function. In a selectional system, in contrast, the predominant role is attributed to the mechanism that recognizes and amplifies certain properties. In the latter case, structural and functional properties exist prior to the arrival of the signal. In his book Synaptic Self, Joseph LeDoux (2002) explains how the brain — or, to be more precise, the synaptic connections between the individual neurons — is shaped by experience:

Selection operates on preexisting (synaptic) connections set up by genes (which make proteins that help guide axons to the right areas) working in concert with non-genetic factors (chemicals from the mother, for example). But genes and the chemical environment are not wholly responsible for establishing the initial connections. Selection also assumes that there is a good deal of randomness involved - terminals and dendrites that happen to be in the same vicinity take the opportunity to form synaptic connections, independent of the overall guidance plan specified by genes. As a result, in spite of the general genetically programmed plan, the preexisting connections upon which selection ultimately operates also have a unique, individualistic nature, from which experience then does the selecting [emphasis added]. Because each person's experiences are different, different patterns of connectivity are selected. Genes thus dictate that we will have a human kind of brain with roughly the same kind of circuits, but random individual differences will exist, and the connectivity of circuits, selected by synaptic activity, will shape the individual's brain (LeDoux, 2002, p 74). 
It is now widely agreed that the evolution of the human cognitive system has been driven by processes of dual-inheritance, that is, gene-culture coevolution (Boyd \& Richerson, 1985; Cavalli-Sforza \& Feldman, 1981; Richerson \& Boyd, 2005). Moreover, human brains are probably more vulnerable to environmental impact than other mammals, due to the extended period of human brain maturation outside the womb. In fact, the increase in brain size and complexity during human infancy is exceptional amongst all primates, the volume of the brain growing by two thirds in the first five years of life. This increase is paralleled by prolonged maturation times with distinctly orchestrated sequences of sculpting grey matter densities and hierarchical myelination processes that proceed from the diencephalon and hindbrain to the cerebellum and pons and from there to the primary and eventually higher areas of the cortex (Deoni et al., 2011; Flechsig, 1901; Toga, Thompson, \& Sowell, 2006). While the increase in brain volume is partly due to the formation of new neurons (neurogenesis), it is mainly attributable to an exponential increase in the growth of synaptic connections, a process called exuberant synaptogenesis (Huttenlocher \& Drabholkar, 1998). When exuberant synaptogenesis is at its peak at around 2 to 3 years of age, the number of synaptic connections increases drastically. Shortly after this period of synaptic growth, the child's brain undergoes a decline in synaptic density. This decline is due to experiential selection (Edelman, 1987): connections that are used more often are strengthened, leading to the consolidation of synaptic connectivities; connections that are used least are weakened or eliminated - synaptic pruning — resulting in the removal of synapses (Craika \& Bialystokb, 2006). Synaptic consolidation, pruning, and synaptogenesis are considered to be important mechanisms underlying learning and memory formation (Gonçalves, Schafer, \& Gage, 2016; Greenough, Black, \& Wallace 1987; Rakic, Bourgeois, \& Goldman-Rakic, 1994; Sweatt, 2016; Toulouse, Dehaene, \& Changeux, 1985). These processes are particularly prominent during distinct stages of children's brain development that have been associated with so-called "critical periods" - periods of high receptiveness to environmental stimuli and thus learning (Drachman, 2005). Thus, the idea that cognition, personality, and behavior are wholly innate or hardwired at birth is strongly contested by neuroscientific research. During ontogeny, more than in later life, the human brain is constantly changing due to experience, social interactions, emotional development, and self-reflection (Chalupa, Berardi, Caleo, Galli-Resta, \& Pizzorosso, 2011).

In addition, a plethora of studies demonstrates that neuroanatomical changes occur not only during critical periods in childhood, but throughout life (for reviews see: Wolff \& Missler, 1992; Gonçalves, Schafer, \& Gage, 2016; and references therein). These structural and functional changes are covered by the umbrella term "neuroplasticity", which denotes the nervous system's capacity to reorganize itself. Neuroplasticity provides mechanisms that shape the neural system in both contextual (social and cultural) and historically dependent (based on previous experience) ways (Doidge, 2007).Human behavior and cognitive skills emerge from multiple processes that are based both on genetic makeup and neuroplastic events. 
International Journal of Child, Youth and Family Studies (2018) 9(1): 9-30

\section{Childhood and Stress}

Infant and juvenile brains are particularly neuroplastic due to processes of neurogenesis, dendritic and synaptic maturation, axon overproduction and elimination, and cortical myelination. This plastic growth and rewiring provides the basis for learning and memory formation. At the same time, this developmental malleability leaves the young brain vulnerable to environmentally induced harm because of its immature neurophysiology (i.e., an immature stress response system). In humans, the developmental phase when large brain reorganizations take place is significantly prolonged (Geschwind \& Rakic, 2013) compared to nonhuman primates. Humans experience an extended childhood and adolescence paralleled by neoteny. Neoteny is characterized by a retention of juvenile physical features like a hairless body, flat face, and large eyes as well as childlike behavior such as playfulness and curiosity. The emergence of neotenic traits in humans is most likely due to sexual selection in human evolution and correlates with a slowed physiological development and a delayed onset of adulthood. Neoteny in humans entails two striking peculiarities: (a) human infants, children, and adolescents have a great capacity for social learning (imitation, observational learning, etc.) due to a highly malleable, neuroplastic brain, especially during the first two decades of life; (b) as a result of this malleability, humans are particularly vulnerable to negative environmental factors.

When humans experience novel stimuli, the sensory cortex is activated and relays the perceived information through the thalamus to the brain stem. The locus coeruleus in the brain stem is the primary site of synthesis of the neurotransmitter noradrenaline. From the locus coeruleus, noradrenergic neurons - those that either secrete or respond to noradrenaline project to many different brain areas such as the hypothalamus, the cerebellum, the cortex, and the amygdala. In an unstimulated, relaxed state, the firing of neurons in the locus coeruleus is at a low baseline level. Upon perception of a novel stimulus the rate of noradrenergic activity in the locus coeruleus increases, which leads to an increase of noradrenaline release to specific brain areas, and this in turn causes a person to become alert and attentive to motivationally significant stimuli. Some behavioral qualities such as curiosity and inventiveness that are associated with neoteny and cultural evolution may be strongly dependent on noradrenergic neurotransmission. In contrast, if an environmental stimulus is perceived as dangerous, the neurons of the locus coeruleus discharge intensely and for a prolonged phase. Noradrenergic transmission can then trigger stress reactions via the hypothalamic-pituitary-adrenal axis (HPA axis) thereby activating the sympathetic nervous system (Thase \& Howland, 1995) and leading to a release of cortisol, adrenaline, and noradrenaline into the body. Each of these hormones or transmitters acts on several body organs, causing the emergence of physiological symptoms (increases in heart rate and respiration, constriction of blood vessels, etc.). From an evolutionary point of view, this is a healthy response to environmental threats because it allows the body to mobilize energy (e.g., by an increase in highly oxygenated blood flow in muscles) when needed to combat or escape adverse situations. 
So that the organism does not end up in a chronic state of stress it is crucial that once the stressful event has passed, the system returns to a resting state. To this end, cortisol or adrenaline/noradrenaline feedback loops lead to a downregulation of the activity of the components of the HPA axis. This is a physiological mechanism that has been retained throughout evolution, is already present in newborns, and is triggered whenever an organism experiences brief adverse events. However, it is important to acknowledge that a child's HPA system is not fully matured and cannot regulate stress reactions efficiently. Children are highly dependent on soothing actions or interventions from the environment in order to calm their excessive bodily stress reactions. It is therefore of paramount importance that parents and caregivers take responsibility for reducing stressful conditions, using soothing activities such as feeding, providing skin contact, and rocking.

Interestingly, rocking movements seem to exert calming effects that help to develop the newborn's cerebellum. This was first demonstrated experimentally in monkeys raised in the company of artificial "surrogate mothers" made of wire-mesh and cloth. Animals raised in this manner grew into socially deviant, highly aggressive adults (Harlow \& Zimmermann, 1959), but less so if the surrogate mothers performed swinging movements. In addition, the monkeys exposed to such artificial "mothers" sit clutching themselves, or holding their heads and bodies in their arms and perform convulsive jerking and rocking movements (Harlow \& Zimmermann, 1959). It is possible that in the young such movements are conveyed to the cerebellum, a part of the brain that has been shown to be crucially involved in motor coordination. The cerebellum and especially a distinct region of it, the cerebellar vermis, develop gradually and continue to create new neurons after birth. In human infants, it is possible that it is the stimulation of the vermis through rocking and other movements that exerts calming effects that help the vermis to develop, which in turn has an effect on the regulation of the stress response. In fact, the vermis contains an extraordinarily high density of receptors for stress hormones. This abundance of stress hormone receptors indicates that exposure to stress hormones can markedly affect the development of this part of the brain. The cerebellum may thus not only be important for motor coordination, but also for compensating for and regulating emotional instability.

Conversely, when prosocial interactions between the infant and significant adults are disrupted (e.g., in the event of neglect, isolation, or abuse) a severe stress reaction is triggered in the infant that cannot be overcome by the child's own physiological mechanisms. As a consequence, activity in the HPA axis is boosted and the sympathetic nervous system suffers chronic overactivation. Lack of sensorimotor interaction between parent and child may impair the capacity of the cerebellar vermis to regulate emotional balance and dampen the stress response. Socially neglected children often show kinetic automatisms or stereotypical back-andforth rocking movements that appear to be desperate attempts to self-soothe and compensate for the lack of social care. Similar rocking behavior has been found in monkeys when they are prevented from forming bonds during the first six months of life (which are roughly equivalent to the first two years of human life). In addition, these monkeys also show signs of severe social 
International Journal of Child, Youth and Family Studies (2018) 9(1): 9-30

disturbances such as withdrawal, impulsiveness, unprovoked aggression, and learning disabilities (Quartz \& Sejnowki, 2002, p. 173).

\section{Nongenetic Mechanisms Influence Social Behavior}

All organisms face sequences of environmental challenges as they grow and develop. To cope with these challenges, organisms possess the capacity for adaptive plasticity; that is, by undergoing changes (acclimatization, learning, etc.) they become better suited to their habitats. Plasticity enhances survival rates in rapidly changing or constantly varying environments. Such nongenetic mechanisms that enable adaptive plasticity are also often called epigenetics. The meaning of the term epigenetics underwent a change over the course of the last century. It was originally coined to describe development and all interactions of products and processes downstream of primary gene products (including neuroplasticity, behavioral plasticity, etc.). Today, however, most researchers use the term to denote temporal and spatial control mechanisms of gene activity that are independent of the DNA sequence (e.g., DNA-methylation, histone modifications, paramutations, imprinting, gene silencing, position effect, maternal effects, etc.).

Epigenetics in the latter sense is a relatively new field of research and studies in humans are thus rare. However, probably the most prominent example of epigenetic research came from some unexpected, yet remarkable findings in humans. These first epigenetic effects observed in humans were found in an epidemiological study on the consequences of malnutrition experienced during the Dutch Famine - the "Hunger Winter" in World War II (Heijmans et al., 2008). The famine caused severe undernutrition in the whole Dutch population, but had especially dramatic effects on pregnant women at that time. The study revealed that this period of food shortage and maternal starvation had a profound effect not only on the intrauterine growth of the babies, but also on their state of health after birth and throughout their lives. In fact, the suffering endured during the "Hunger Winter" has been identified as one of the major contributors to chronic disease in later life for those born at that time (Roseboom, de Rooij, \& Painter, 2006). These findings have been referred to as the "fetal programming hypothesis" (Barker, 2004). According to this hypothesis maternal undernutrition restricts intrauterine development and thus leads to lower birthweights in newborns. The mother's deficient diet signals to the fetus that post-birth and long-term living conditions will be impoverished. In response, the development of the fetus follows an altered course, leading to changes in body size and metabolism that will help prepare for harsh conditions after birth. In this way, low birthweight babies are better adapted to a deficient environment than babies of mothers who were pregnant in an environment of abundance. However, when the living conditions improve from the anticipated dearth to abundance, the low birthweight babies become maladapted. Such babies are at a higher risk of diseases - obesity, diabetes, cardiovascular disease, and mental illnesses such as depression - in later life, since the individual's metabolism is adapted to an

environment of shortage. It is likely that the developmentally plastic effects are attributable to epigenetic mechanisms that induce the genes to express a wide range of physiological or 
morphological states in response to environmental conditions during critical periods in early fetal development (Bateson, 2001). Once triggered, these plastic effects become manifest in persistent, lifelong changes in the body structure and function. What is most noteworthy is that studies have revealed (Bygren et al., 2014; Dominguez-Salas, Cox, Prentice, Hennig, \& Moore, 2012; Susser et al., 2012) a correlation between the nutritional status of pregnant women and the health of not only their children, but even their grandchildren. This indicates the possibility that some epigenetic changes can be transmitted over at least two generations.

Other research on epigenetics comes from animal studies and investigates the effect of maternal brood care on offspring social behavior. There are some naturally occurring variations in the responses of mother rats to stress in their offspring. Pups that receive ample licking and grooming after birth become more stress resistant and are more open to new experiences and exploratory behavior (Meaney, 2001; Weaver, Meaney, \& Moshe, 2006) than pups that have received little care. Thus, an increase in maternal care and physical contact appears to be an important factor in resilience. Significantly, the extent of rats' maternal brood care influences not only the immediate offspring, but also subsequent generations, and is a nongenetic inheritance process. Animals that have experienced neglecting maternal behavior will also behave less affectionately towards their own offspring. However, since these effects are nongenetic, they can be reversed by exposing newborn pups to more caring foster mothers. After having experienced intensive brood care from foster mothers, the female pups of neglecting mothers will eventually become more affectionate mothers as adults.

Studies on parental care in humans also support the importance of physical contact and affectionate relations between parents and children (Brauer, Xiao, Poulain, Friederici, \& Schirmer, 2016; McLaughlin, Sheridan, \& Nelson, 2017; Moore et al., 2017). Both skin contact and suckling during breastfeeding trigger the release of the bonding hormone oxytocin. Oxytocin is released in the baby as well as in the mother, helping to consolidate a positive mother-baby relationship. Interestingly, recent evidence has indicated that skin contact between fathers and their newborns also triggers oxytocin release in both baby and father (Vittner et al., 2018). Oxytocin is a highly interesting candidate for research on social cognition and behavior, since it has been shown to play a crucial role in attachment, social exploration, and social recognition, as well as in anxiety and stress-related behaviors (Meyer-Lindenberg, Domes, Kirsch, \& Heinrichs, 2011). Experimental administration of oxytocin in combination with social support dampens neuroendocrine stress reactivity and decreases amygdala activation in response to threatening stimuli (Kirsch et al., 2005).

Molecular genetic studies have identified variations in the gene (i.e., genetic polymorphism) coding for the oxytocin receptor within healthy individuals. These variations in the oxytocin receptor gene are modestly associated with differences in sociobehavioral phenotypes, such as prosocial behavior, parenting, empathy, positive affect, and sensitivity to social support or support seeking during stress (Kumsta \& Heinrichs, 2013). But polymorphism of the oxytocin receptor gene revealed only small sociobehavioral effects within humans. In 
contrast, variations of gene expression of the oxytocin receptor gene by epigenetic factors seem to have a stronger influence on interindividual differences in social cognition and behavior. Epigenetic changes in the regulatory sequences of the oxytocin receptor correlate with high levels of callousness and unemotionality and differential activation of brain regions involved in social perception (Kumsta, Hummer, Chen, \& Heinrichs, 2013). These changes can be dynamically regulated by exposure to psychosocial stress. In addition, adult women with a history of early abuse have lower oxytocin concentrations in their cerebrospinal fluid than women without such negative experiences (Heim et al., 2009). Prolonged deprivation in early childhood seems to interfere with the developing oxytocin system. Postinstitutionalized children who had been reared in severely depriving conditions and later adopted showed lower peripheral oxytocin levels after physical interactions with their adoptive mothers than adopted children who had been reared in a typical home environment (Wismer Fries, Ziegler, Kurian, Jacoris, \& Pollak, 2005). Thus, traumatic experiences seem to have a negative effect on the developing oxytocin system and probably have adverse effects on attachment and bonding, anxiety, social recognition, and maternal care as well.

\section{Alleged Maladaptation to Cultural Niches}

The above examples of nongenetic inheritance lead us to a discussion of the role that individuals themselves play in the generation of their surroundings and habitats. Scholars have increasingly pointed out that organisms are not simply subject to selective pressure and environmental influences in a passive way, but can themselves actively alter their own environments in a feedback loop; this dynamic interactive process has been termed niche construction (Lewontin, 1983; Odling-Smee, Laland, \& Feldman, 2003). Several biologists have argued that niche construction is as important to evolution as natural selection is (Laland, Matthews, \& Feldman, 2016; Odling-Smee, Laland, \& Feldman, 2003). Niche construction has been documented for many species, such as beavers, which alter their ecosystems by constructing dams, and earthworms, which affect the chemical composition of the soil they live in. Of all species, however, humans provide the most striking examples of niche construction in that they generate cultural, as well as ecological, niches. Above all, it is the cognitive mechanisms shaped by humans in the course of evolution that provide the substrate for creating our social and cultural environments. Examples of such mechanisms include recognizing oneself as a mental agent, and inferring the psychological states of other individuals, both of which are prerequisites for developing a theory of mind, and for qualities such as empathy. Thus, "one person's nature is another person's nurture" (Wexler, 2006, p. 16). Humans are capable of adapting rapidly to changes in the cultural world, thereby accelerating the timescale of change from a slow, evolutionary one to a fast, developmental one in which changes occur within historical time. Thus, culture helps to shape the brain, which creates culture, which again acts on the brain (Quartz \& Sejnowski, 2002, p. 58-59). This feedback loop reverberates throughout 
decades or centuries and is an example of cultural niche construction. ${ }^{1}$ Such man-made niches foster certain cognitive or behavioral traits, while attenuating others. This process can be transmitted over generations, since descendants usually inherit their ancestors' niches and pass them on to their children. In this respect, the inheritance of ecological and cultural niches is, like epigenetics, a form of nongenetic inheritance mechanism. It might be especially these kinds of nongenetic inheritance that are responsible for the exponential increase in the diversity of human behavior (Smith, 2011). While many of the behavioral and cognitive traits that result from such reinforced social interactions within a given niche are highly adaptive (e.g., social learning and teaching behaviors, prosocial child rearing practices, and pair bonding), some may be highly nonadaptive (e.g., addictive or self-destructive behavior).

Since the appearance of modern humans, our cultural environment has changed drastically. Our biology and presumably many of our behaviors underwent significant adaptation during the period when our ancestors lived as hunter-gatherers . A hunter-gatherer lifestyle is characterized by low-fat diets, little technology, high mobility, low birth rates with relatively long intervals (4 years) between births, exclusive breastfeeding for the first two years, low population density, and living in small (25 to 50 people), kin-based social groups (Dunbar, 1993). Clearly, the cognitive and behavioral traits that were advantageous for this lifestyle were different from those that are adaptive in most societies today. This concept has become known as evolutionary mismatch theory (Diggs, 2017; Lloyd, Wilson, \& Sober, 2011); it refers to negative consequences that result from a trait that evolved in one environment being carried over into another environment. Examples of evolutionary mismatches include eating disorders, addictive behaviors, vertigo, and certain types of anxieties. With the onset of agriculture, humans gave up their nomadic lives, shifted their diets, started to live in larger communities (which exposed them to a higher risk of infectious diseases), and reduced the intervals between births, with a resulting increase in birth rates (Bocquet-Appel, 2008). Many of the previously selected traits were no longer advantageous. Researchers claim that many characteristics and behaviors that evolved and had adaptive value during our evolutionary history may be maladaptive in some modern contexts (Trevathan, Smith, \& McKenna, 1999), as modern humans have to adapt to many different niches, with significantly different values and norms.

Transient changes in positive and negative states help individuals to fine-tune their adjustment tactics, allowing them to cope with everyday social life in their particular niche. For example, being in high spirits increases fitness in situations of opportunity, whereas being in low spirits allows the person to stop investing in hopeless endeavors and encourages the quest for

\footnotetext{
1 "In the niche construction approach, members of a species can alter the environment, and thus how selective pressures act on them. Niche modifying creates a feedback loop from behavior to environment to selection in ways that are not generally represented in most evolutionary scenarios. The niche construction model appears to be an extremely robust way of thinking about brain evolution for neuroanthropology because it offers a way to bring together thinking about how patterns of environmental change represent simultaneously adaptation and selective pressure, as subsequent generations face the cumulative effects of altered developmental and evolutionary landscapes" (Lende \& Downey, 2003, p. 118).
} 
alternative strategies or enterprises. As an example of the latter, children raised almost exclusively by neglecting or abusive parents, without the support of other adult members (i.e., alloparents) who could compensate for the maltreatment, will show responses such as fear and sadness that help them to cope with this adverse situation. In this view, human attachment theory (Bowlby, 1960) can be interpreted from an evolutionary perspective, which suggests that abnormal styles of attachment, specifically anxious attachment and ambivalent attachment, may in fact be adaptive in certain situations (Chisholm, 1996). If a mother is disinclined to invest in a child, ordinary secure attachment may be less beneficial for the infant than anxious or avoidance attachment. In fact, such defense mechanisms based in aversive emotions shaped by evolution may help toddlers to survive the stressful situation of not gaining or maintaining proximity to attachment figures. A seemingly inappropriate behavior, such as the anxious and solitary behavior of an infant in an abusive family, can therefore be adaptive in a certain cultural niche. However, the same behavior may turn out to be maladaptive in other social niches, such as when the individual resorts to anxious behavior in an adult relationship or in a new, caring foster family. Such maladaptive responses are then experienced as stressful. Consequently, later in life, individuals will seek out niches that match previously established internal, mental structures shaped in response to the external social and cultural milieus of their early childhoods. This will usually be reflected in their adult relationships (with partners or friends), and may also affect their choices of other cultural niches such as work places, professional associations, political and governmental affiliations, religious congregations, and various interest groups. This process of active creation and selection of environments has been termed "niche picking" (Scarr \& McCartney, 1983) in the psychological literature. In fact, each person is usually a member of multiple overlapping cultural niches. Some of these niches may be better matches for an individual's "inner landscape" than others, and humans are usually successful in intuitively finding social niches that are similar to those to which they have been exposed during childhood. Interestingly, similar findings have been shown in animals. When mice are in states of high arousal, they will preferentially return to familiar places where they experienced physical pain rather then seeking out less familiar places not associated with punishment (Mitchell, Koleszar, \& Scopatz, 1984).

In cases where the available external environment does not match the internal structures, people act to manipulate the environment to make it match their internal structures rather than modify their internal structures (Wexler, 2006). This concept can help to explain why, when abused or neglected children become parents themselves, they once more create abusive or neglecting familial environments. This may initially seem surprising, given the findings that the human brain remains extremely malleable and plastic throughout life and is capable of producing different behavioral patterns. However, it is important to note that neuroplasticity decreases in the course of brain maturation. In the adult brain, neuroplastic events are still taking place in various areas of the neocortex, but occur to a lesser extent in other brain regions. 
Emotions play a pivotal role in evaluating whether a social niche matches the inner structure. Neuroscientists have shown that human emotions are not located in a single brain area, but involve several interconnected brain circuits. Emotions are short-lived physical states that are universally similar across all humans. They have evolved as quick, bodily responses to external stimuli. For the most part our emotional responses are processed nonconsciously and subcortically. The mental associations and reactions that emotions give rise to are feelings, which are influenced by personal experience, beliefs, and memories, and thereby assign meaning to emotions. Only when higher processes in neocortical regions of the brain are engaged do we experience feelings, and so become conscious of emotions (Damasio, 1994). In fact, emotions and feelings seem to involve different neural pathways that fulfill distinct functions. Emotional processes, automatic, quick, and nonconscious, are often described as the "low road" of the system (LeDoux, 1996). When a stimulus is perceived, it is relayed via the thalamus directly to the limbic system, where it is processed automatically. This low road gives the individual the chance to react rapidly and instinctively to putative dangers by engaging the amygdala, a part of the limbic system that can activate the fight-or-flight response via the HPA axis. In contrast, the "high road" involves the neocortex, giving the individual the opportunity for flexibility, thoughtfulness, and choice, but at the cost of a slower reaction time. This path activates higher thinking processes that allow rational interpretation of the situation. The quick, low road response evolved as a lifesaver in dangerous situations. This neural pathway is automatically activated when a person feels threatened by actual or presumed dangers, which may cause an overreaction of the amygdala. Components of the limbic system, especially the amygdala, provide organisms with the ability to assess and respond quickly to social stimuli. Thus, as it navigates social life, the emotional brain continuously appraises environmental stimuli for positive or negative valence, safety, and danger (Fishbane, 2007).

In contrast, the high road involving the neocortex attenuates quick responses, allowing us to consider various options by integrating conscious information. By incorporating reciprocal neural pathways between the prefrontal cortex and the limbic system, emotions can guide "rational" decision making. A part of the prefrontal cortex, the orbitofrontal cortex acts as a regulator of the limbic system, particularly by dampening immediate reactions of the amygdala. The orbitofrontal cortex retains its neuroplasticity throughout life and ensures that we can respond flexibly when new or additional information becomes available. The interplay between limbic and prefrontal functions permits us to make behavioral choices that are in line with our long-term goals and values. For example, going against our initial inner impulse, we may decide not to shout at the boss after being wrongfully criticized because we do not want to risk losing our job.

But the high route of feelings is not the dominant pathway. The connections from the amygdala to the prefrontal cortex are stronger than the connections in the opposite direction, which explains why emotions can easily overwhelm a person and impair "rational" decision making (LeDoux, 1996). This is even more so when the limbic system is constantly challenged 
by an abusive environment during the period of maturation of the amygdala shortly after birth (Jedd et al., 2015; Pechtel \& Pizzagalli, 2011). Traumatic experiences, abuse, and neglect can also strongly interfere with the adaptive shaping of the functioning of the orbitofrontal cortex (which continues to mature well into adulthood), thereby compromising judgment and selfcontrol (Hanson et al., 2010).

In addition to neuroplastic events affecting the gross architecture of the brain, high levels of childhood stress can also alter overall levels of neurotransmitters, especially serotonin and noradrenaline (De Bellis \& Zisk, 2014). Noradrenaline is a crucial component of the HPA axis and involved in stress response. The levels of different neurotransmitters act as an internal guidance system that colors an individual's world with positive and negative value and conveys this information to higher brain areas to inform decision making (Quartz \& Sejnowski, 2002, p. 196). Developmentally traumatic experiences can resculpture the behavior of a child's noradrenaline system, causing him or her to live in a relabeled world in which positive and negative valuations are biased toward the negative. As a result, the individual's brain detects dangerous signals everywhere and sends errant alarms to higher cognitive areas, putting the natural defense system in a permanent alert state. A shift in the serotonin system can lead to impairment in sociability and impulse control. Lack of maternal care in nonhuman primates leads to reduced levels of serotonin, which in turn correlates with greater aggression, more alcohol consumption, and more anxiety-like behaviors during the animals' adolescence (Suomi, 2003). It is therefore possible that lower serotonin levels in stressed brains wire the brain for extreme and unpredictable violence that may spark a cycle of aggressive behavior and social illiteracy (Quartz \& Sejnowski, 2002, p. 196).

When survivors reexperience responses from developmentally traumatic events in the past - very often without their being able to remember the actual situation in their personal history - they fall back into a reactive state of self-protection and survival behavior. This triggers an immediate, nonconscious reaction via the low route, leading to an increase in the firing rate of the amygdala and activating the HPA axis; at the same time, signals from the orbitofrontal cortex are not integrated in the response of the limbic system; that is, the high route is underfunctioning. Negative social triggers such as feeling criticized or attacked can activate this low route and lead to a strong overreaction. Moreover, even situations that appear normal to other people, such as a crying baby, can trigger an overreaction in a developmentally traumatized parent, due to neurotransmitter systems that are out of balance. The parent then feels unable to cope with the situation and reexperiences an adverse childhood situation in which a similar emotional state was aroused. This emotional state of fear and helplessness is nonconsciously experienced by the parent as a threat to wellbeing and triggers a reactive survival behavior, the fight-or-flight response. However, as an adult, the developmentally traumatized person has an extended potential for action that was not available as an infant. An emotionally overwhelmed parent may act upon the "fight" response and become abusive. Alternatively, such a parent may act upon the "flight" response and become neglecting. In both cases self-control via the higher 
International Journal of Child, Youth and Family Studies (2018) 9(1): 9-30

cortical route is overridden. Acting upon such developmentally early response mechanisms from the limbic system, and excluding higher cognitive processes, leads to situations that are emotionally similar to those experienced in early childhood. Hence, the parent has "successfully" generated a social niche in which maltreatment continues and is socially transmitted to the next generation. Similarly, this scenario can also explain secondary traumatization in professionals and other people close to a traumatized person insofar as they are exposed to a familiar social niche constructed by the victim.

\section{Neurobiological Mechanisms of Acute Trauma and Developmental Psychological Trauma}

Developmental psychological traumas as described above refer to stressful events that occur repeatedly and cumulatively over an extended time and within specific relationships and contexts (Courtois, 2004). Among the experiences that can constitute chronic traumatization are sexual, emotional, and physical childhood abuse, physical and emotional neglect, and severe poverty. However, other experiences that are limited to a single or a few events of highly negative emotional impact can also cause traumas. These experiences involve serious injury or threat to life or limb, and often lead to symptoms of posttraumatic stress disorder (PTSD). PTSD was first identified in combat veterans, but it has since been shown that it can also occur in survivors of natural disasters, rape, and other life-threatening or devastating incidents (van der Kolk, 2014; Howlett \& Stein, 2016). People with PTSD, who have experienced acute trauma, show psychological reaction patterns and behaviors that are somewhat different from those of people who have experienced chronic traumatic events in early childhood. People with PTSD repeatedly reexperience the traumatic event in the awake state or in dreams. Thus, the intense emotions experienced during the traumatic events are manifested in visceral sensations such as heightened anxiety and panic attacks, as well as in vivid visual images and other acute sensory perceptions such as flashbacks and nightmares (van der Kolk, 1994).

As far as other symptoms go, research on both PTSD and developmental psychological trauma suggests that they have overlapping mechanisms and most likely rely on comparable physiological and neurobiological processes (van der Kolk, 2014). Both people with PTSD and those with developmental psychological trauma may suffer a numbing of their responsiveness, show reduced interest in activities, limit the range of their emotions, and have feelings of detachment or estrangement from others. In addition, some may also experience heightened arousal (causing difficulty in falling or staying asleep), irritability or outbursts of anger, difficulties in concentrating, hypervigilance, and an exaggerated startle response.

Although on the face of it the psychological effects of PTSD seem more pronounced (panic attacks, flashbacks, nightmares) than those of developmental trauma, this impression is misleading. Such differences can most likely be attributed to differences in the duration and age of onset of the traumatic incidents. The longer the aversive situation lasted, and the earlier in development it took place, the more time the victim has had for psychosocial adjustment and to restructure his or her inner landscape to adapt to the abusive environment. Moreover, traumatic 
experience in early childhood may not be remembered because of naturally occurring infantile amnesia. However, this by no means indicates that the neuropsychological damage is less in early developmental trauma. It is simply less evident to the untrained eye. In fact, it can be assumed that traumatic events of longer duration and earlier onset will have more dramatic and penetrative effects with respect to neuroplastic restructuring of the individual's brain. In the case of chronic or developmental trauma, the person will run continuously on a psychological "emergency program", while in the case of acute trauma, the person may suffer from episodic outbursts of defense reactions. In a metaphor, one could describe the former as a silent scream from the body and brain, and the latter as an open cry for help.

In fact, it has been demonstrated that the more stressful an experience and the longer its duration, the more severely memory and learning are disrupted (Shapero et al., 2014). An important neurobiological mechanism underlying disruptions in memory and learning is the release of toxic amounts of corticosteroids from the stress response circuit when chronically high levels of stress are experienced. Cells in the hippocampus, the crucial brain area underlying memory formation and retrieval, have an unusually large number of receptors that respond to corticosteroids such as cortisol. High levels of corticosteroids attack brain cells in the developing hippocampus, initiate a process of shrinking of neuronal protrusions, lead to neuronal cell death, and ultimately result in permanent damage to the hippocampus (Bremner et al., 1997). In addition, the hippocampus is one of the few parts of the brain that not only develops gradually, but also continues to produce new cells after birth. As demonstrated in rodents, corticosteroids inhibit neurogenesis (the generation of new neurons) in the hippocampus (Karten, Olariu, \& Cameron, 2005). Taken together, it can be assumed that situations of chronic maltreatment lead to both damage to the hippocampus and inhibition of the development of new hippocampal neurons, which interfere with both memory and learning.

This impairment might explain why highly traumatic events often cannot be consciously recalled and lead to lacunar and situation-specific amnesia. In such severe cases of neural deterioration due to toxic exposure to corticosteroids and inhibited neurogenesis (and other mechanisms not discussed here), partial or complete recovery of memory may never occur because conscious recollection apparently requires an involvement of the hippocampus. Yet, the emotional information associated with the traumatic events might nonetheless be stored in the procedural memory system, which matures earlier and is less sensitive to corticosteroids. In some cases, when the victim returns to an emotional state of arousal similar to the one in which the memory was stored (i.e., state dependent learning), this familiarity can trigger retrieval of the event. The reason for this may be that the latter type of recall (familiarity) seems to be mediated by areas of the medial temporal lobe rather than the hippocampus (Diana, Yonelinas, \& Ranganath, 2007).

In contrast to the described states of amnesia, clinicians working with PTSD sufferers have also observed hypermnesia, in which sensory experiences and visual images related to the trauma do not fade over time and remain much more vivid than other, ordinary memory traces. 
International Journal of Child, Youth and Family Studies (2018) 9(1): 9-30

The more unexpected and the less compatible an event is relative to a person's worldview or their view of a person, the more difficult it will be to integrate such traumatic experiences around a coherent and enduring sense of self within his or her world. Patients with severe traumatization are often unable to put the trauma behind them, become fixated on the past, reenact the trauma, and are unable to incorporate the event into their personal history (van der Kolk, 1994). Moreover, not only may they fail to integrate the stressful experience into their self-narrative, but they may not even be aware of this psychological incoherence. Since the ability to form a coherent self-image lies at the core of our capacity to generate a view of life in general, such disruptions can have devastating consequences. For example, a person might be unable to link his or her current behavior with his or her future self. Consequences of punishment will then not seem threatening because the self who commits the crime will not be linked with the self that has to face the punishment (Quartz \& Sejnowski, 2002, p. 197).

\section{Conclusion}

Since childhood and adolescence are extended in humans, our brains have evolved the capacity to become significantly sculptured by our social and physical environments, and especially by our experiences early in life. This neuroplasticity enables our brains to adapt to our specific social surroundings advantageously. It is also the basis for lifelong adaptation and changes in our brain. The malleability of the brain provides the flexibility needed to live in different cultural niches and respond to new challenges throughout life. However, if the developing brain of a child or an adolescent is exposed to traumatic events, the integration of higher cognitive processes by means of plasticity is to some degree sacrificed for evolutionarily older "emergency" programs that aim for bare survival. Thus, the brains of maltreated individuals seem to develop along rigid, enduring paths, with less of the malleability found in unimpeded development. Consequently, severe childhood abuse is not something that one can grow out of and get over. It alters a person's neurobiological and biochemical makeup and thereby his or her behavior, cognition, and state of mind. Neuroscience is only just beginning to grasp the dimensions of the underlying mechanisms and consequences of abuse. It will require broad interdisciplinary efforts to tackle the most urgent research questions in this field, disseminate relevant research, and face this societal challenge by speaking for those who have been muted by maltreatment. 
International Journal of Child, Youth and Family Studies (2018) 9(1): 9-30

\section{References}

Azmitia, E. C. (2007). Cajal and brain plasticity: Insights relevant to emerging concepts of mind. Brain Research Reviews, 55, 395-405. doi:10.1016/j.brainresrev.2007.01.010

Bach-y-Rita, P. (1967). Sensory plasticity. Acta Neurologica Scandinavica, 43, 417-42. doi:10.1111/j.1600-0404.1967.tb05747.x

Barker, D. J. P. (2004). The developmental origins of adult disease. Journal of the American College of Nutrition, 23, 588S-595S. doi:10.1080/07315724.2004.10719428

Baron-Cohen, S. (2003). The essential difference. New York, NY: Basic Books

Bateson, P. (2001). Fetal experience and good adult design. International Journal of Epidemiology, 30, 928-934. doi:10.1093/ije/30.5.928

Bocquet-Appel, J.-P. (2008). Explaining the Neolithic demographic transition. In J.-P. BocquetAppel \& O. Bar-Yosef (Eds.), The Neolithic demographic transition and its consequences (pp. 35-55). Dordrecht, Netherlands: Springer.

Bowlby, J. (1960). Separation anxiety: A critical review of the literature. The Journal of Child Psychology and Psychiatry, 1, 251-269. doi:10.1111/j.1469-7610.1960.tb01999.x

Boyd, R., \& Richerson, P. J. (1985). Culture and the evolutionary process. Chicago, IL: University of Chicago Press.

Brauer, J., Xiao, Y., Poulain, T., Friederici, A. D., \& Schirmer, A. (2016). Frequency of maternal touch predicts resting activity and connectivity of the developing social brain. Cerebral Cortex, 26, 3544-3552. doi:10.1093/cercor/bhw137

Bremner, J. D., Randall, P., Vermetten, E., Staib, L., Bronen, R. A., Mazure, C., ... Charney, D. S. (1997). Magnetic resonance imaging-based measurement of hippocampal volume in posttraumatic stress disorder related to childhood physical and sexual abuse - a preliminary report. Biological Psychiatry, 41, 23-32. doi:10.1016/S0006-3223(96)00162-x

Brizendine, L. (2006). The female brain. New York, NY: Broadway Books.

Bygren, L. O., Tinghög, P., Carstensen, J., Edvinsson, S., Kaati, G., Pembrey, M. E., \& Sjöström, M. (2014). Change in paternal grandmothers' early food supply influenced cardiovascular mortality of female grandchildren. BioMed Central Genetics, 15(12). doi:10.1186/1471-2156-15-12

Cavalli-Sforza, L. L., \& Feldman, M. W. (1981). Cultural transmission and evolution: A quantitative approach. Princeton, NJ: Princeton University Press. 
International Journal of Child, Youth and Family Studies (2018) 9(1): 9-30

Chalupa, L. M., Berardi, N., Caleo, M., Galli-Resta, L., \& Pizzorosso, T. (2011). Cerebral plasticity: New perspectives. Cambridge, MA: MIT Press.

Chisholm, J. S. (1996). The evolutionary ecology of attachment organization. Human Nature, 7 , $1-37$.

Courtois, C. A. (2004). Complex trauma, complex reactions: Assessment and treatment. Psychotherapy: Theory, Research, Practice, Training, 41, 412-425. doi:10.1037/0033$\underline{3204.41 .4 .412}$

Craik, F. I. M., \& Bialystok, E. (2006). Cognition through the lifespan: Mechanisms of change. Trends in Cognitive Sciences, 10, 131-138. doi:10.1016/j.tics.2006.01.007

Damasio, A. (1994). Descartes' error: Emotion, reason, and the human brain. New York, NY: Putnam.

De Bellis, M. D., \& Zisk, A. (2014). The biological effects of childhood trauma. Child and Adolescent Psychiatric Clinics of North America, 23, 185-222. doi:10.1016/j.chc.2014.01.002

Deoni, S. C. L., Mercure, E., Blasi, A., Gasston, D., Thomson, A., Johnson, M., ... Murphy, D. G. M. (2011). Mapping infant brain myelination with magnetic resonance imaging. Journal of Neuroscience, 31, 784-791. doi:10.1523/JNEUROSCI.2106-10.2011

Diana, R. A., Yonelinas, A. P., \& Ranganath, C. (2007). Imaging recollection and familiarity in the medial temporal lobe: A three-component model. Trends in Cognitive Sciences, 11, 379-386. doi:10.1016/j.tics.2007.08.001

Diggs, G. M., Jr. (2017). Evolutionary mismatch: Implications far beyond diet and exercise. Journal of Evolution and Health, 2(1), Art. 3. doi:10.15310/2334-3591.1057

Doidge, N. (2007). The brain that changes itself: Stories of personal triumph from the frontiers of brain science. London, UK: Penguin Books.

Dominguez-Salas, P., Cox, S. E., Prentice, A. M., Hennig, B. J., \& Moore, S. E. (2012). Maternal nutritional status, C1 metabolism and offspring DNA methylation: A review of current evidence in human subjects. Proceedings of the Nutrition Society, 71, 154-165. doi:10.1017/S0029665111003338

Drachman, D. A. (2005). Do we have brain to spare? Neurology, 64, 2004-2005. doi:10.1212/01.WNL.0000166914.38327.BB

Dunbar, R. I. M. (1993). Coevolution of neocortical size, group size and language in humans. Behavioral and Brain Sciences, 16, 681-735. doi:10.1017/S0140525X00032544 
International Journal of Child, Youth and Family Studies (2018) 9(1): 9-30

Edelman, G. M. (1987). Neural Darwinism: The theory of neuronal group selection. New York, NY: Basic Books.

Fishbane, M. D. (2007). Wired to connect: Neuroscience, relationships, and therapy. Family Process, 46, 395-412. doi:10.1111/j.1545-5300.2007.00219.x

Flechsig, P. (1901). Developmental (myelogenetic) localisation of the cerebral cortex in the human subject. Lancet, 158, 1027-1030. doi:10.1016/S0140-6736(01)01429-5

Geschwind, D. H., \& Rakic, P. (2013) Cortical evolution: Judge the brain by its cover. Neuron, 80, 633-647. doi:10.1016/j.neuron.2013.10.045

Golgi, C. (1898) Intorno alla struttura della cellula nervosa [Concerning the structure of the nerve cell]. Bolletino - Societa Medico Chirurgica Pavia, 13, 3-16.

Gollin, E. S. (1981). Developmental plasticity: Behavioral and biological aspects of variation in developmental. New York, NY: Academic Press.

Gonçalves, J. T., Schafer S. T., \& Gage F. H. (2016). Adult neurogenesis in the hippocampus: From stem cells to behavior. Cell, 167, 897-914. doi:10.1016/j.cell.2016.10.021

Greenough, W. T., Black, J. E., \& Wallace, C. S. (1987). Experience and brain development. Child Development, 58, 539-559.

Grossi, G. (2017). Hardwiring: Innateness in the age of the brain. Biology \& Philosophy. doi:10.1007/s10539-017-9591-1

Hanson, J. L., Chung, M. K., Avants, B. B., Shirtcliff, E. A., Gee, J. C., Davidson, R. J., \& Pollak, S. D. (2010). Early stress is associated with alterations in the orbitofrontal cortex: A tensor-based morphometry investigation of brain structure and behavioral risk. Journal of Neuroscience, 30, 7466-7472. doi:10.1523/JNEUROSCI.0859-10.2010

Harlow, H. F., \& Zimmermann, R. R. (1959). Affectional responses in the infant monkey. Science, 130, 421-432. doi:10.1126/science.130.3373.421

Heijmans, B. T., Tobi, E. W., Stein, A. D., Putter, H., Blauw, G. J., Susser, E. S., ... Lumey, L. H. (2008). Persistent epigenetic differences associated with prenatal exposure to famine in humans. Proceedings of the National Academy of Sciences of the United States of America, 105, 17046-17049. doi:10.1073/pnas.0806560105

Heim, C., Young, L. J., Newport, D. J., Mletzko, T., Miller, A. H., \& Nemeroff, C. B. (2009). Lower CSF oxytocin concentrations in women with a history of childhood abuse. Molecular Psychiatry, 14, 954-958. doi:10.1038/mp.2008.112 
International Journal of Child, Youth and Family Studies (2018) 9(1): 9-30

Howlett, J. R., \& Stein, M. B. (2016). Post-traumatic stress disorder: Relationship to traumatic brain injury and approach to treatment. In D. Laskowitz \& G. Grant (Eds.), Translational research in traumatic brain injury (Ch. 16). Boca Raton, FL: CRC Press/Taylor and Francis Group. Retrieved from https://www.ncbi.nlm.nih.gov/books/NBK326723/

Huttenlocher, P. R., \& Dabholkar, A. S. (1998). Regional differences in synaptogenesis in human cerebral cortex. Journal of Comparative Neurology, 387, 167-178. doi:10.1002/(SICI)1096-9861(19971020)387:2<167::AID-CNE1>3.0.CO;2-Z

Jedd, K., Hunt, R. H., Cicchetti, D., Hunt, E., Cowell, R. A., Rogosch, F. A., .. Thomas, K. M. (2015). Long-term consequences of childhood maltreatment: Altered amygdala functional connectivity. Development and Psychopathology, 27, 1577-1589. doi:10.1017/S0954579415000954

Kandel, E. R., Schwartz, J. H., \& Jessell, T. M. (2000. Principles of Neural Science (4th ed.). New York, NY: McGraw-Hill, Health Professions Division.

Karten, Y. J. G, Olariu, A., \& Cameron, H. A. (2005). Stress in early life inhibits neurogenesis in adulthood. Trends in Neurosciences, 28, 171-172. doi:10.1016/j.tins.2005.01.009 Kirsch, P., Esslinger, C., Chen, Q., Mier, D., Lis, S., Siddhanti, S., ... Meyer-Lindenberg, A. (2005). Oxytocin modulates neural circuitry for social cognition and fear in humans. Journal of Neuroscience, 25, 11489-11493. doi:10.1523/JNEUROSCI.3984-05.2005

Kumsta, R., \& Heinrichs, M. (2013). Oxytocin, stress and social behavior: Neurogenetics of the human oxytocin system. Current Opinion in Neurobiology, 23, 11-16. doi:10.1016/j.conb.2012.09.004

Kumsta, R., Hummel, E., Chen, F. S., \& Heinrichs, M. (2013). Epigenetic regulation of the oxytocin receptor gene: Implications for behavioral neuroscience. Frontiers in Neuroscience, 7, art. 83. doi:10.3389/fnins.2013.00083

Laland, K., Matthews, B., \& Feldman, M. W. (2016). An introduction to niche construction theory. Evolutionary Ecology, 30, 191-202. doi:10.1007/s10682-016-9821-Z

LeDoux, J. E. (1996). The emotional brain: The mysterious underpinnings of emotional life. New York, NY: Simon \& Schuster.

LeDoux, J. E. (2002). Synaptic self: How our brains become who we are. New York, NY: Viking.

Lende, D. H., \& Downey, G. (2003). The encultured brain: An introduction to neuroanthropology. Cambridge, MA: MIT Press.

Lewontin, R. C. (1983) Gene, organism and environment. In D. S. Bendall (Ed.), Evolution from molecules to men (pp. 273-285). Cambridge, MA: Cambridge University Press. 
International Journal of Child, Youth and Family Studies (2018) 9(1): 9-30

Lillard A. S., \& Erisir A. (2014). Old dogs learning new tricks: Neuroplasticity beyond the juvenile period. Developmental Review, 31, 207-239. doi:10.1016/j.dr.2011.07.008

Lloyd, E., Wilson, D. S., Sober, E. (2011) Evolutionary mismatch and what to do about it: A basic tutorial [Internet]. Retrieved from: https://evolution-institute.org/wpcontent/uploads/2015/08/Mismatch-Sept-24-2011.pdf

Lugaro, E. (1909). Modern problems in psychiatry (D. Orr \& R. G. Rows, Trans.). Manchester, UK: The University Press. As reviewed in The British Journal of Psychiatry, 55, 748749. doi:10.1192/bjp.55.231.748

McLaughlin, K. A., Sheridan, M. A., \& Nelson, C. A. (2017). Neglect as a violation of speciesexpectant experience: Neurodevelopmental consequences. Biological Psychiatry, 82, 462471. doi:10.1016/j.biopsych.2017.02.1096

Meaney, M. J. (2001). Maternal care, gene expression, and the transmission of individual differences in stress reactivity across generations. Annual Review of Neuroscience, 24, 1161-1192. doi:10.1146/annurev.neuro.24.1.1161

Meyer-Lindenberg, A., Domes, G., Kirsch, P., \& Heinrichs, M. (2011). Oxytocin and vasopressin in the human brain: Social neuropeptides for translational medicine. Nature Reviews Neuroscience, 12, 524-538. doi:10.1038/nrn3044

Mitchell, D., Koleszar, A. S., \& Scopatz, R. A. (1984). Arousal and T-maze choice behavior in mice: A convergent paradigm for neophobia constructs and optimal arousal theory. Learning and Motivation, 15, 287-301. doi:10.1016/0023-9690(84)90024-9

Mitchell, C., Schneper, L. M., \& Notterman, D. A. (2016). DNA methylation, early life environment, and health outcomes. Pediatric Research, 79, 212-219. doi:10.1038/pr.2015.193

Moore, S., McEwen, L., Quirt, J., Morin, A., Mah, S., Barr, R., ... Kobor, M. (2017). Epigenetic correlates of neonatal contact in humans. Development and Psychopathology, 29, 15171538. doi:10.1017/S0954579417001213

Odling-Smee, J. F., Laland, K. N., \& Feldman, M. W. (2003). Niche construction: The neglected process in evolution. Princeton, NJ: Princeton University Press.

Pechtel, P., \& Pizzagalli, D. A. (2011). Effects of early life stress on cognitive and affective function: An integrated review of human literature. Psychopharmacology, 214, 55-70. doi:10.1007/s00213-010-2009-2

Quartz, S. R., \& Sejnowski, T. J. (2002). Liars, lovers, heroes. New York, NY: Harper Collins. 
International Journal of Child, Youth and Family Studies (2018) 9(1): 9-30

Rakic, R., Bourgeois, J.-P., \& Goldman-Rakic, P. S. (1994) Synaptic development of the cerebral cortex: Implications for learning, memory, and mental illness. In J. van Pelt, M. A. Corner, H. B. M. Uylings, \& F. H. Lopes da Silva (Eds.), Progress in Brain Research, 102, 227-243. doi:10.1016/S0079-6123(08)60543-9

Richerson, P. J., \& Boyd, R. (2005). Not by genes alone: How culture transformed human evolution. Chicago, IL: University of Chicago Press.

Roseboom, T., de Rooij, S., \& Painter, R. (2006). The Dutch famine and its long-term consequences for adult health. Early Human Development, 82, 485-491. doi:10.1016/j.earlhumdev.2006.07.001

Scarr, S., \& McCartney, K. (1983) "How people make their own environments: A theory of genotype $\rightarrow$ environment effects. Child Development, 54, 424-435. doi:10.2307/1129703

Shapero, B. G., Black, S. K., Liu, R. T., Klugman, J., Bender, R. E., Abramson, L. Y., \& Alloy, L. B. (2014). Stressful life events and depression symptoms: The effect of childhood emotional abuse on stress reactivity. Journal of Clinical Psychology, 70, 209-223. doi:10.1002/jclp.22011

Smith, E. A. (2011). Endless forms: Human behavioural diversity and evolved universals. Philosophical Transactions of the Royal Society B: Biological Sciences, 366, 325-332. doi:10.1098/rstb.2010.0233

Suomi, S. J. (2003). Gene-environment interactions and the neurobiology of social conflict. Annals of the New York Academy of Sciences, 1008, 132-139. doi:10.1196/annals.1301.014

Susser, E., Kirkbridge, J. B., Heijmans, B. T., Kresovich, J. K., Lumey, L. H., \& Stein, A. D. (2012). Maternal prenatal nutrition and health in grandchildren and subsequent generations. Annual Review of Anthropology, 41, 577-610. doi:10.1146/annurev-anthro-081309-145645

Sweatt, J. D. (2016). Neural plasticity and behavior - sixty years of conceptual advances. Journal of Neurochemistry, 139, 179-199. doi:10.1111/jnc.13580

Szyf, M. (2011). DNA methylation, the early-life social environment and behavioral disorders. Journal of Neurodevelopmental Disorders, 3, 238-249. doi:10.1007/s11689-011$\underline{9079-2}$

Thase, M. E., \& Howland, R. H. (1995). Biological processes in depression: An updated review and integration. In E. E. Beckham \& W. R. Leber (Eds.), Handbook of depression (pp. 213279). New York, NY: Guilford Press.

Toga, A. W., Thompson, P. M., \& Sowell, E. R. (2006). Mapping brain maturation. Trends in Neurosciences, 29, 148-159. doi:10.1016/j.tins.2006.01.007 
International Journal of Child, Youth and Family Studies (2018) 9(1): 9-30

Tognini, P., Napoli, D., \& Pizzorusso, T. (2015). Dynamic DNA methylation in the brain: A new epigenetic mark for experience-dependent plasticity. Frontiers in Cellular Neuroscience, 9, 1-11. doi:10.3389/fncel.2015.00331

Toulouse, G., Dehaene, S., \& Changeux, J.-P. (1985). Spin glass model of learning by selection. Proceedings of the National Academy of Sciences of the United States of America, 83, 16951698.

Trevathan, W. R., Smith, E. O., \& McKenna, J. J. (1999). Evolutionary medicine. Cambridge, MA: MIT Press.

van der Kolk, B. A. (1994). The body keeps the score: Memory and the evolving psychobiology of posttraumatic stress. Harvard Review of Psychiatry, 1, 253-265. doi:10.3109/10673229409017088

van der Kolk, B. A. (2014). The body keeps the score: Brain, mind, and body in the healing of trauma. New York, NY: Viking.

Vittner, D., McGrath, J., Robinson, J., Lawhon, G., Cusson, R., Eisenfeld, L., ... Cong, X. (2018). Increase in oxytocin from skin-to-skin contact enhances development of parentinfant relationship. Biological Research for Nursing, 20, 54-63. doi: $10.1177 / 1099800417735633$

Weaver, I. C. G., Meaney, M. J., \& Moshe, S. (2006). Maternal care effects on the hippocampal transcriptome and anxiety-mediated behaviors in the offspring that are reversible in adulthood. Proceedings of the National Academy of Sciences of the United States of America, 103, 3480-3485. doi:10.1073/pnas.0507526103

Wexler, B. E. (2006). Brain and culture: Neurobiology, ideology, and social change. Cambridge, MA: MIT Press.

Wismer Fries, A. B., Ziegler, T. E., Kurian, J. R., Jacoris, S., \& Pollak, S. D. (2005). Early experience in humans is associated with changes in neuropeptides critical for regulating social behavior. Proceedings of the National Academy of Sciences of the United States of America, 102, 17237-17240. doi:10.1073/pnas.0504767102

Wolff, J. R., \& Missler, M. (1992). Synaptic reorganization in developing and adult nervous systems. Annals of Anatomy, 174, 393-403. doi:10.1016/S0940-9602(11)80257-8 